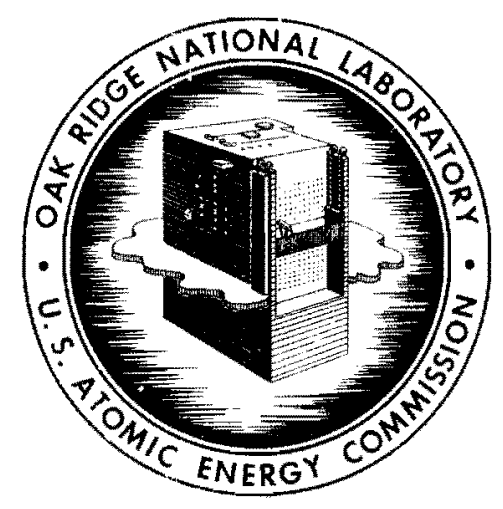

OAK RIDGE NATIONAL LABORATORY

operated by

UNION CARBIDE CORPORATION

for the

U.S. ATOMIC ENERGY COMMISSION

\author{
ORNL - TM-218- $-(\mathcal{A}$ \\ COPYNO. - 17 \\ DATE - JUIY 20, 1962
}

DEVELOPMENT OF REGENERATIVE COMPRESSOR FOR HELIUM CIRCULATION

I. K. Namba

\begin{abstract}
Compressors were required to circulate helium coolant in an in-pile loop at moderately high heads (6000-8000 ft), at low volumetric flows $(30-40 \mathrm{acfm})$, at $600^{\circ} \mathrm{F}$ and $385 \mathrm{psig}$. A regenerat.ive type of gas compressor, using grease-lubricated ball bearings enclosed in a special water-cooled casing, was designed and tested. The design objectives were achieved, and a number of these compressors have been built and are in operatior.
\end{abstract}

\title{
NOTICE
}

This document contains information of a preliminary nature and was prepared primarily for internal use at the Oak Ridge National Laboratory. It is subject to revision or correction and therefore does not represent a final report. The information is not to be abstracted, reprinted or otherwise given public dis. semination without the approval of the ORNL patent branch, Legal and information Control Department. 


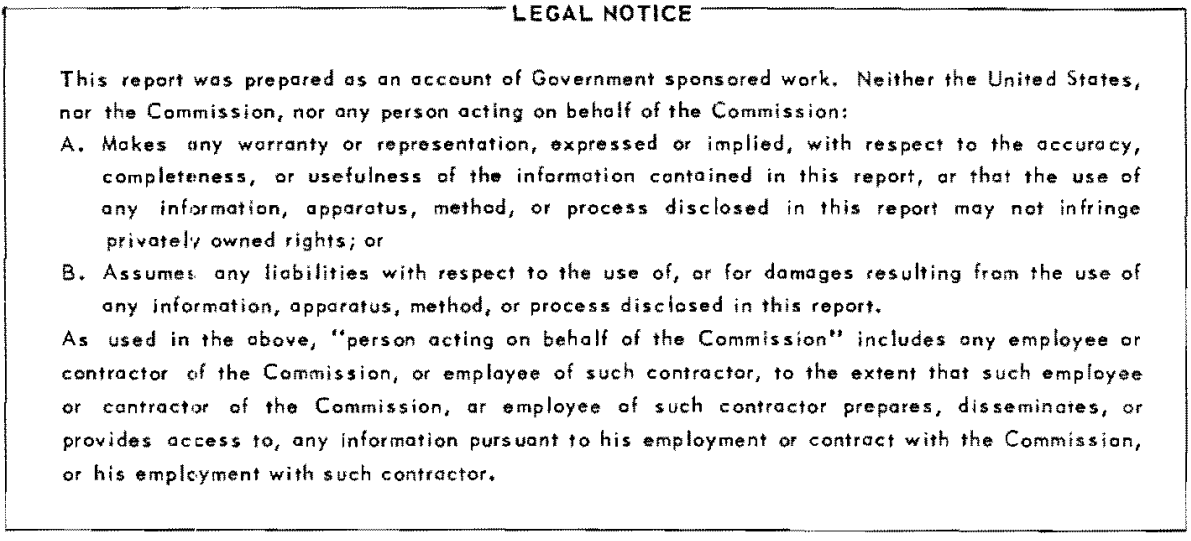


DEVELOPMENT OF REGENERATIVE COMPRESSOR FOR HELIUM CIRCULATION

I . K. Namba

INTRODUCTION

A set of helium compressors was needed to circulate helium coolant in an in-pile irradiation facility. The compressors were required to produce heads considerably higher than those normally expected of centrifugal compressor units, at flow rates well below the optimum design range for centrifugal compressors. The units were required to operate without maintenance for minimum periods of 3000 to $4000 \mathrm{hr}$.

Previous investigations had shown that comercially available compressors could not meet all of the requirements f'or the present application. A centrifugal compressor suitable f'or the required conditions of pressure and temperature had been previously designed and tested by the Reactor Division. ${ }^{1}$ Further investigations showed that it should be possible to obtain the required aerodynamic characteristics by adapting a regenerative-type of impeller for use with the water-cooled motor and bearing housing previously developed for the centrifugal compressor.

This report describes the equipment used for two air test models and the results of these model tests, as well as the design, construction, and test of the final regenerative units.

PRINCIPIE OF OPERATION OF THE REGENERATIVE COMPRESSOR

The regenerative compressor is also reterred to in the literature as a "peripheral", a "turbine", or a "drag" compressor. While this configuration has been used primarily for pumping liquids, several theories, supported by semi-empirical expressions, have been presented in the literature to explain the behavior of this type of unit when used to

${ }^{I} I \cdot K \cdot$ Namba, Development of Centrifugal Compressors, ORNL-TM-63, (Oct. 9, 1961). 
circulate gases. The circulatory flow theory, ${ }^{2}$ describes the mechanism of the pumping action in terms of the centrifugal field induced by the rotating impeller. Figure 1 illustrates schematically the aerodynamic elements of the regenerative compressor. The impeller has radial vanes machined into each side around its periphery. As the impeller rotates in the direction of flow, the fluid is passed through the vanes to the periphery of the impeller and then directed back into the root of other impeller vanes. This recirsulation occurs many times through a large number of vanes as the fluid travels from suction to discharge, and can be thought of as producing a multi-stage or regenerative effect. The fluid path is geometrically similar to a helical spring bent in an incomplete circle, with each cycle adding energy to the fluid in a form of pressure head. Iverson ${ }^{3}$ and senoo consider turbulent friction between the moving impelier and the fluid as the primary force causing the pumping action. These authors advance the idea that the pumping mechanism is induced by the shearing stresses created in the fluid by the impeller.

\section{PRELIMINARY EXPERIMENTS}

Very little experimental intormation was available as a basis for the design of a regenerative impel.ler. A first test was made of the pertormance of a 5-in. diameter regererative impeiler operating in water, and the results of this test were then converted to anticipate a performance characteristic in air.

F. A. Wilson, M. A. Santalo, and J.A. Oelrich, "A Theory of the Fluid-Dynamic Mecharism of Regenerative Pumps," Trans. Am. Soc. Mech. Engrs. 17, 1303-10 (Nov., 1955).

${ }^{3} \mathrm{H}$. W. Iverson, "Pertormance of the Periphery Pump," Trans. Am. Soc. Mech. Engrs. 77, 19-28 (Jan., 1955).

${ }^{4} \mathrm{Y}$. Senoo, "A Comparison of Regenerative-Pump Theories Supported by New Pertormance Data," Trans. Am. Soc. Mech. Engrs. 78, 1091-1102, (July, 1956). 

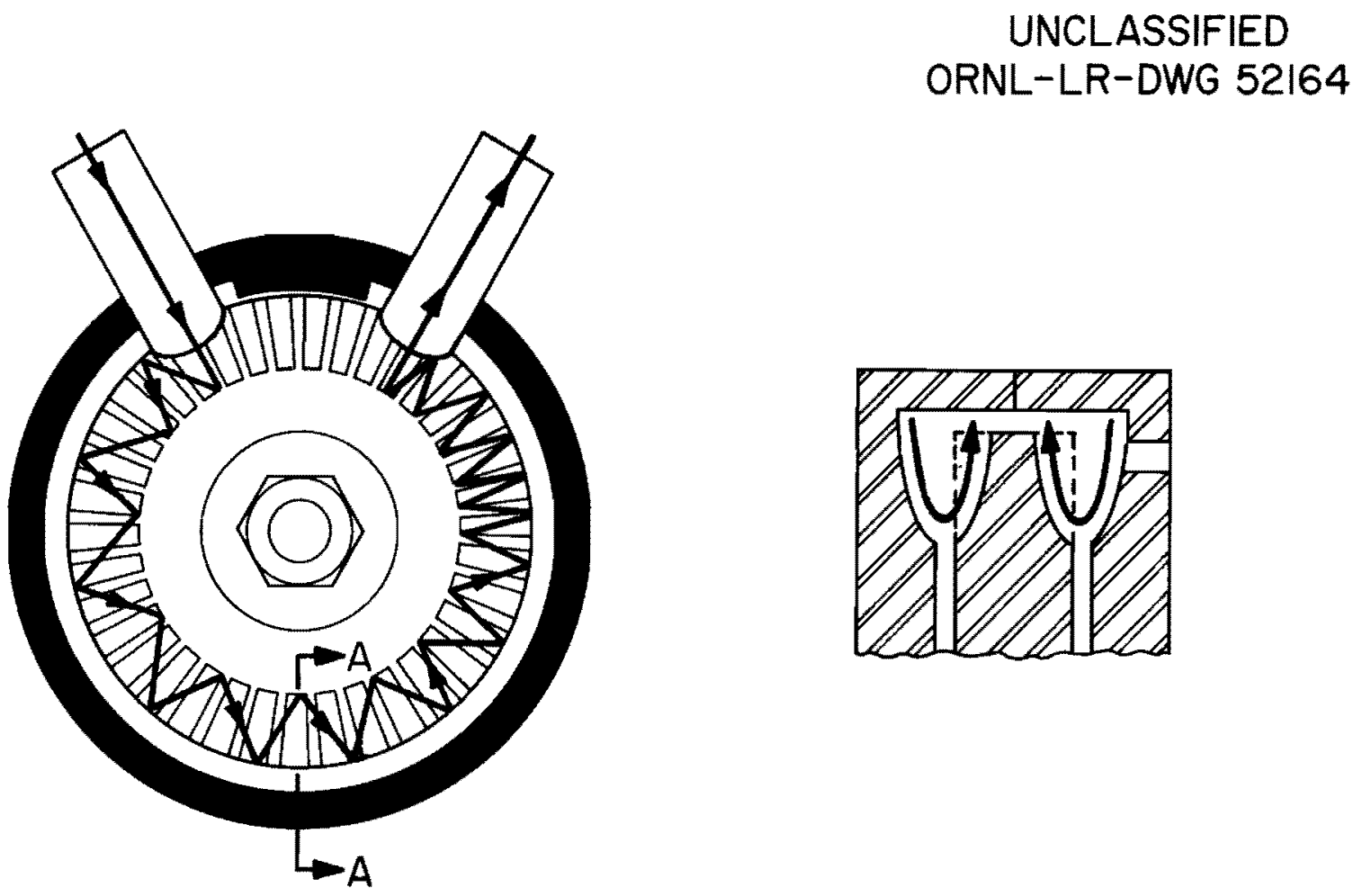

Fig. 1. Schematic of Regenerative Wheel. 
An extrapolation of the water tests to helium operating conditions indicated that a wheel diameter of $10 \mathrm{in}$. should satisfy the aerodynamic requirements of the proposed loop. The calculated disc stresses and the peripheral speed of the impeller suggested the use of stainless steel material for the experimental wheel. The spacing and number of vanes of the impeller were an engineering compromise between mechanical rigidity of the fins and the optimum number of vanes for conveyance of fluid momentum from the impeller.

Figure 2 shows the apparatus used for the air tests. The rotary member, consisting of shaft, motorarotor and impeller, was supported on pillow-block flange-mounted ball bearings. The experimental impeller had 59 equally spaced vanes, machined on each side, with the vanes staggered half pitch on the opposite sides. The impeller was mounted on the shaft and sandwiched between two close-fitting casings. A teflon packing ring was used for a shaft seal. Pressure tap connections were provided by drilling twelve equaliy spaced $1 / 8$-in. holes on the circumference of the impeller casings, and also at the center of the outboard casing. For the suction and discharge ports, two 1 1/4-in. openings were machined radially into the casings on either side of the splitter of the constant area flow channel. A magnetic-type speed indicator pickup was mounted on the shaft. A 400-cycle, 4-pole motor, rated at $20 \mathrm{hp}$ and driven by a motor-generator set, supplied the power to drive the impeller during the tests.

After assembly of the experimental impelier and drive system, the test rig was piped in conformance with ASME testing requirements. The instrumentation included a throttle valve, an orifice flowmeter, and a bank of mercury-filled manometers for pressure measurements.

Some difficulties were encountered in the early test runs in establishing adequate runing clearances. The use of axial clearances betwinn the impeller and the casing of $0.005 \mathrm{in}$. at each side, and of a 0.007-in. radial clearance at the stripper, were found to be satisfactory. Filler plates had been provided so that the depth of the peripheral flow channel could be varied, and performance data were obtained at speeds from 6000 to $12000 \mathrm{rpm}$, for three different flow channel depths, at the clearances mentioned above. Figure 3 shows the head-flow characteristics of the experimental compressor, operated under the above conditions. 


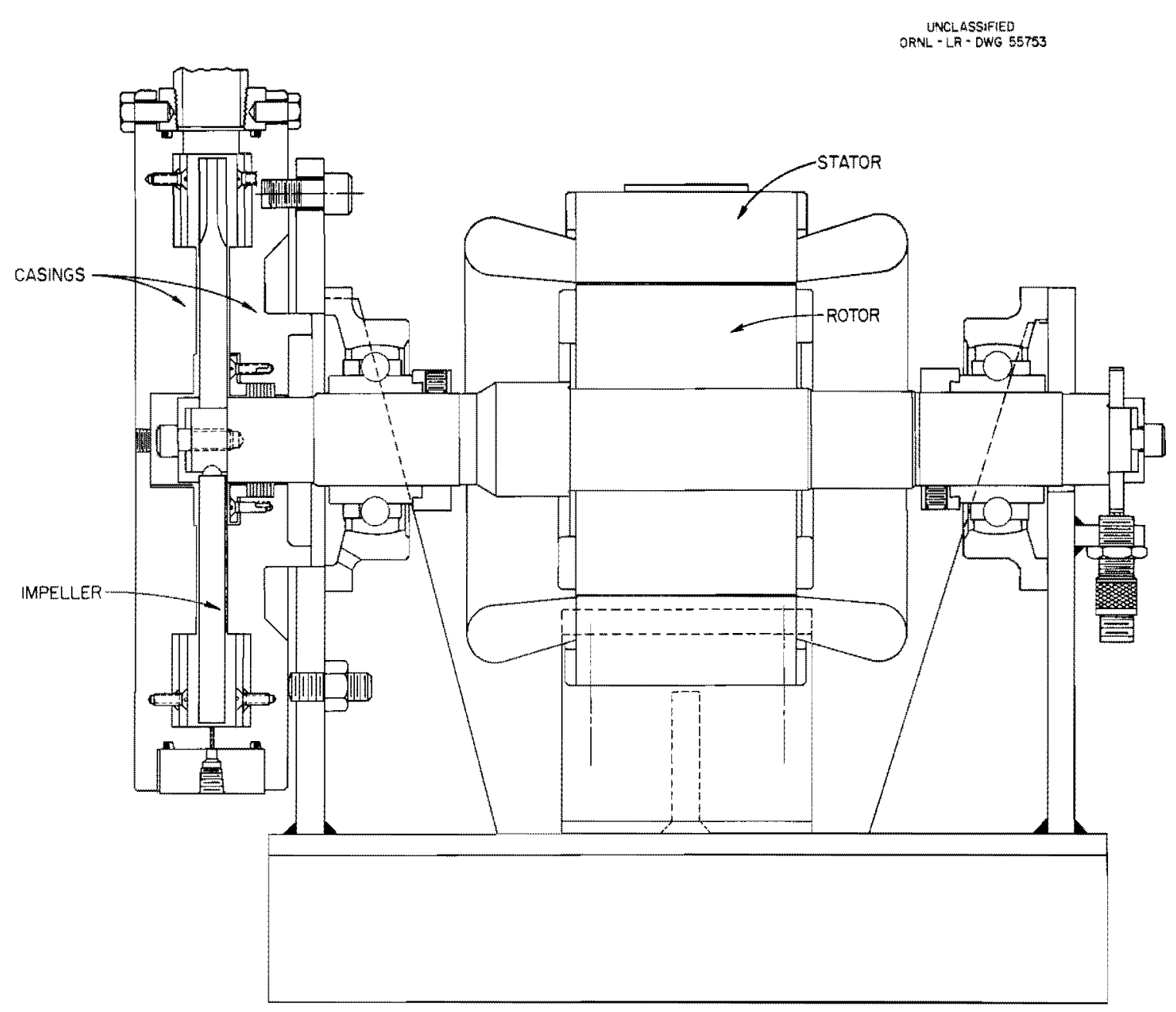

Fig. 2. Regenerative Impeller Air Test Stand. 

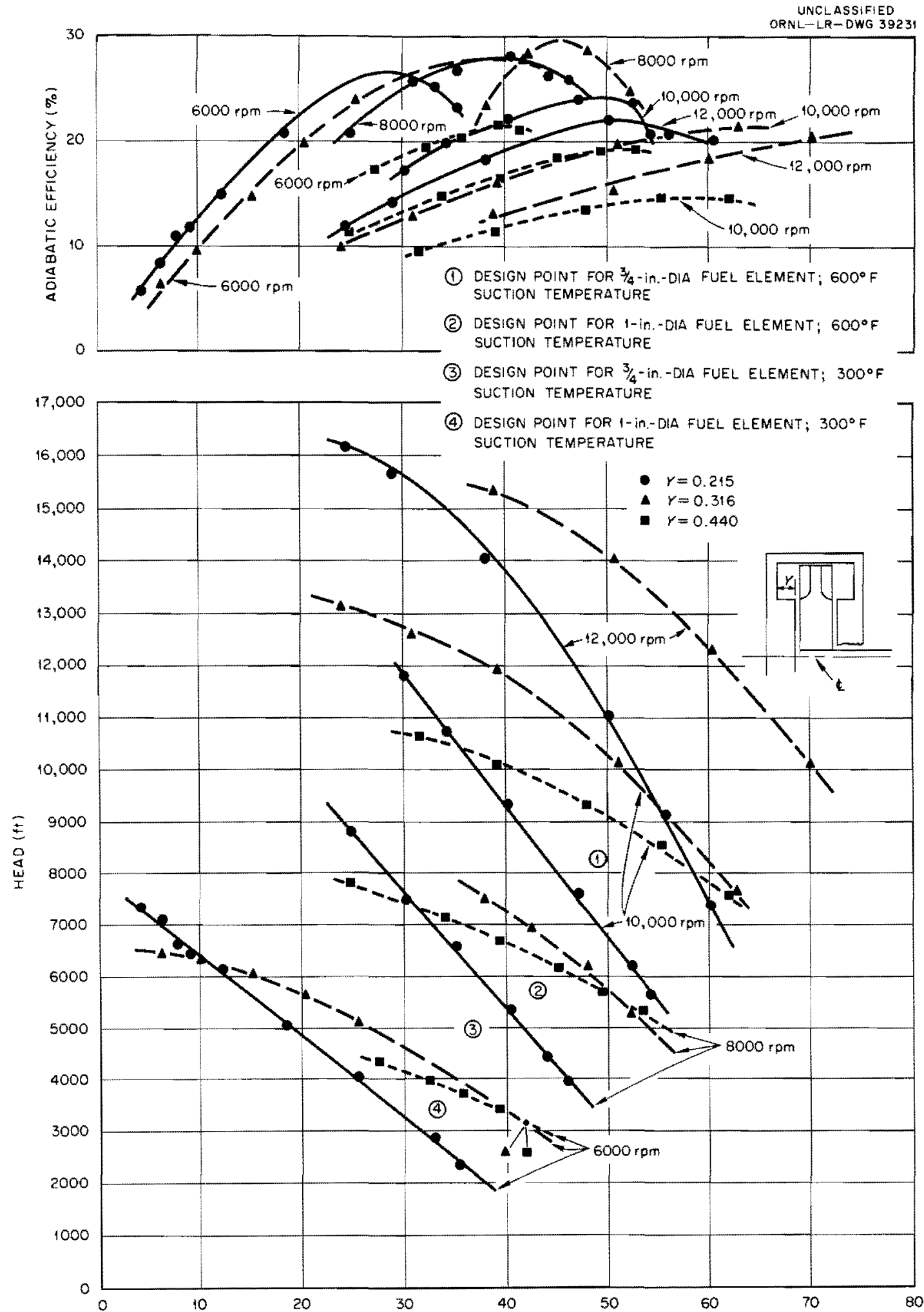

Fig. 3. Air Flow in CFM at Suction Conditions of $85^{\circ} \mathrm{F}$ and 14.7 psia vs Head and Erficiency. 


\section{DESCRIPTION OF PROTOTYPE COMPRESSOR}

The design of the motor and bearing housing for the regenerative compressor, including the design of the cooling passages, was based on an earlier design used for a centrifugal compressor. ${ }^{5}$ The design of many of the parts for the two different types of unit was essentially identical, but it was necessary to make a number of modifications to permit the replacement of the centrifugal impeller by a regenerative impeller.

Figure 4 shows a cross section of the prototype regenerative compressor. The impeller and motor rotor were mounted on a common shaft, supported on grease-lubricated ball bearings. Water cooling passages were provided by machining double-helical or double-spiral coolant passage ways, as shown in the figure. Additional heat sink capacity was provided by means of an annular coolant flow passage placed inside the hollow shaft. A thermal radiation barrier was placed between the hot gas surfaces and the bearing housing to help minimize heat transfer to the latter. A thermal sleeve arrangement was used to attach the impeller housing to the compressor housing to eliminate a sharp thermal gradient which would otherwise have existed. Barden 107H angular contact-type ball bearings were used, with a 90-1b preload. ${ }^{6}$ The water-cooling circuit was designed to maintain the temperature of these bearings at approximately $150^{\circ} \mathrm{F}$ during normal operation. A 4-pole, shell-type induction motor, rated at $20 \mathrm{hp}$ at $12000 \mathrm{rpm}$ ( $400 \mathrm{cps}$ ), insulated with Class H insulation was used. The motor was designed for constant torque operation at frequencies between 200 to 400 cycles. The ratio of the applied voltage-to-frequency was 0.52 . The motor was driven by an electrically driven variable speed motorgenerator set.

Figure 5 shows a perspective view of the regenerative impeller, which has a 10-in. diameter, and a symmetrical blading arrangement having 50

\footnotetext{
${ }^{5}$ I. K. Namba, op. cit., pp 2-4.
}

${ }^{6}$ Communication from H.R. Berglund, Barden Corp., Danbury, Conn., Oct. 15, 1959, to A. G. Grindell, ORNL. 

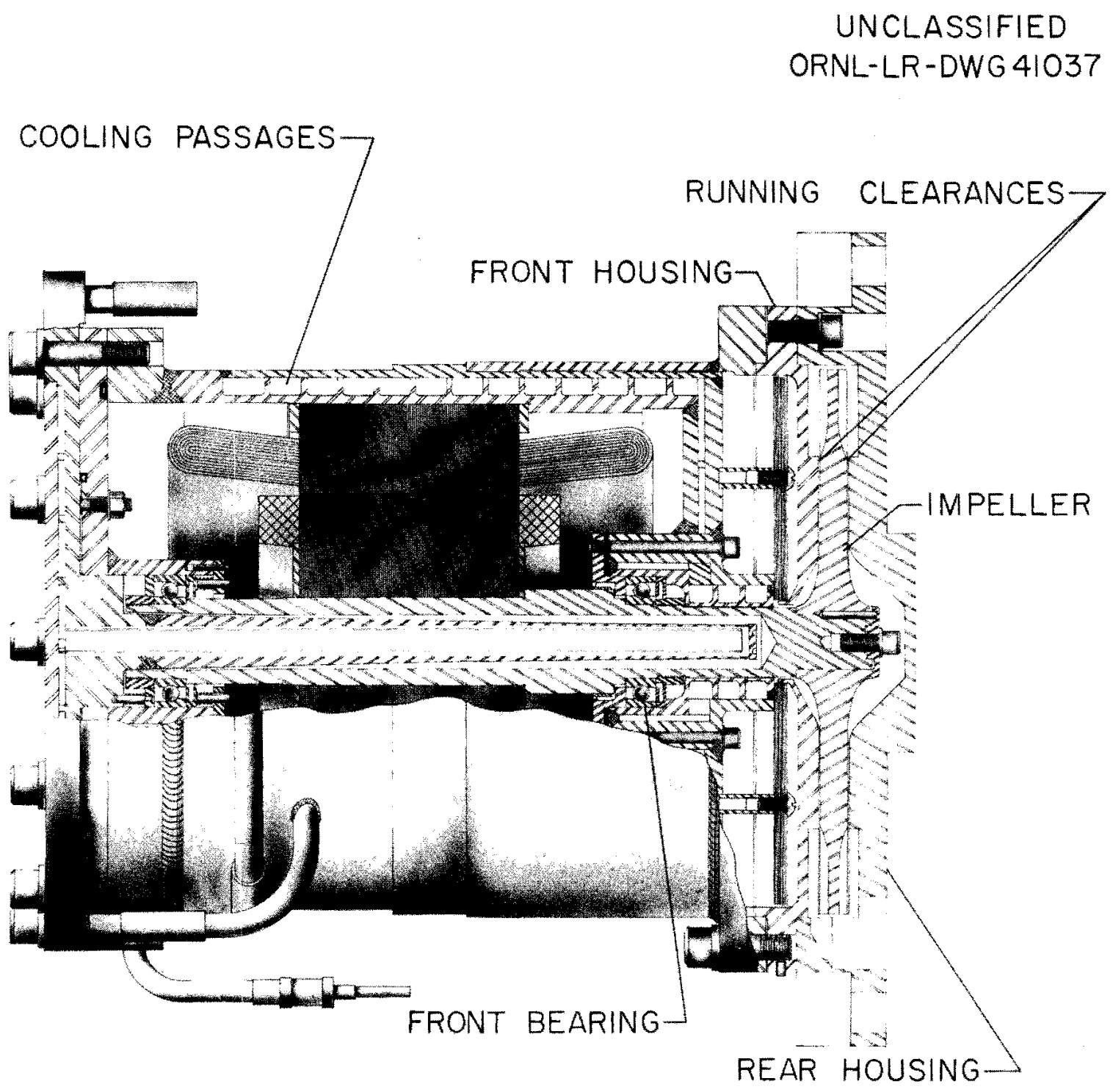

Fig. 4. Regenerative Compressor (HECT-2 Type). 


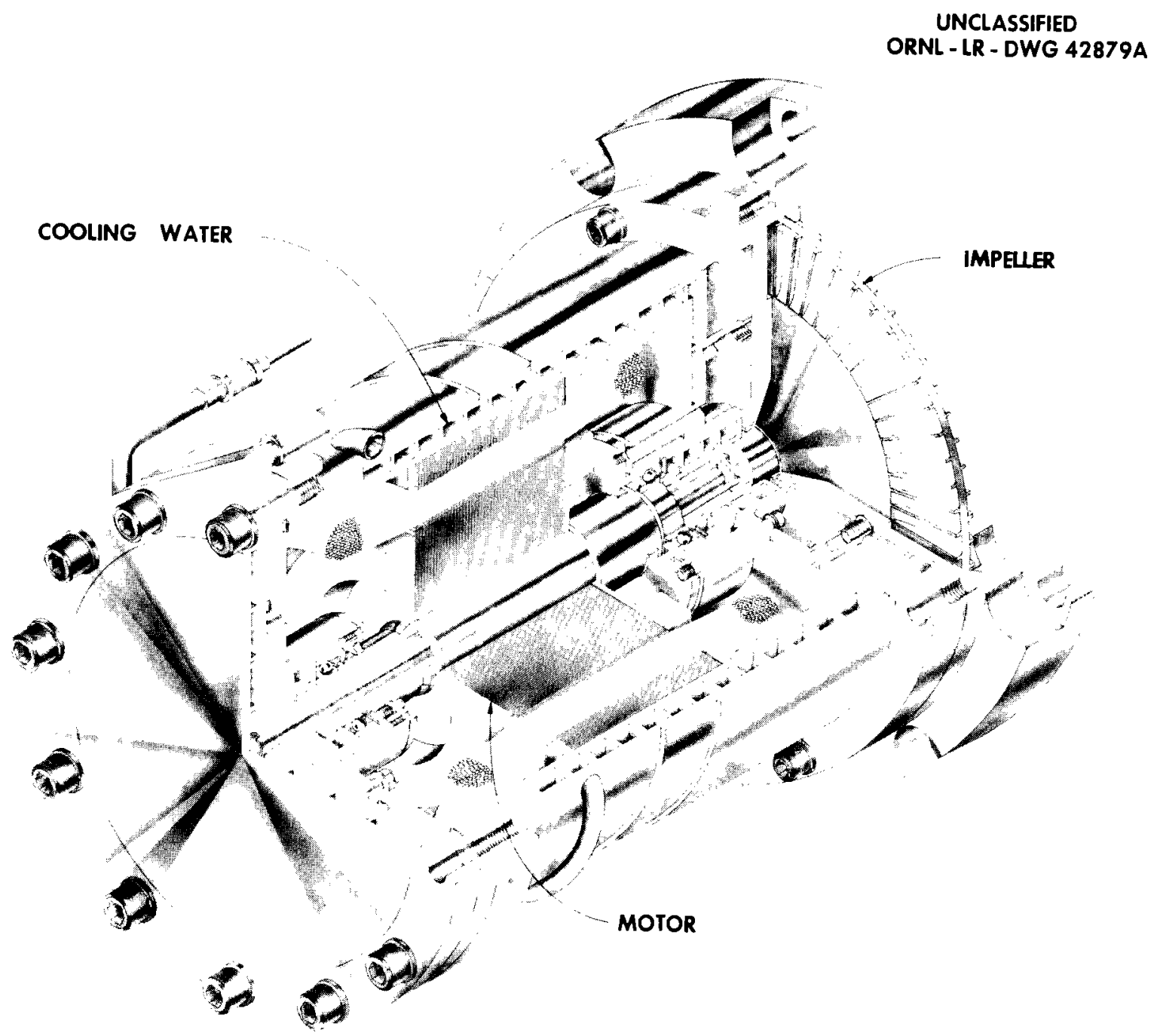

Fig. 5. Regenerative Compressor. 
equally spaced vanes on each face, staggered at half-pitch on opposite faces. The impeller was mounted between two casings whth small radial and axial running clearances.

All major components of the compressor were fabricated from Inconel, with the exception of the steel used in the electric motor.

\section{TEST EQUIPMENT}

The closed-circuit test loop used in testing the compressor is shown in Fig. 6. The compressor was installed in a pressure vessel with its shaft horizontal to conform to the configuration used in the final test loop. Since the compressor package was designed to operate at temperatures up to $600^{\circ} \mathrm{F}$, the pressure vessel, piping, throttling valve, and orifice meter were made of types 316 and 347 stainless steel. Several banks of clam-shell type electrical heaters were mounted on the loop piping to maintain the required operating temperatures. Dry helium supplied from cylinders was admitted to the loop piping through a regulator valve.

\section{INSTRUMENTATION}

The necessary instrumentation was provided on the compressor and test apparatus to obtain over-a.l performance data under varying conditions of temperature and pressure. Helium weight-flow measurements were made with a sharp-edged orifice run, and a throttling valve was used to vary the gas flow. Static taps were connected to the suction and discharge lines to measure the pressure differential across the compressor. Thermocouples were placed on various sections of the loop and compressor for temperature indication and for high-temperature control purposes. In order to protect the compressor bearings, alarms were provided to indicate low coolant flow and high bearing and loop gas temperatures, together with automatic tripouts to de-energize the loop heaters and compressor motor circuits if the loop gas temperature exceeded a preset point. An electronic counter (Hewlett-Packard) was used to determine the impeller speed.

A Fielden proximity meter, in combination with capacitance gages, was used to determine the axial clearance between the impeller and the two 


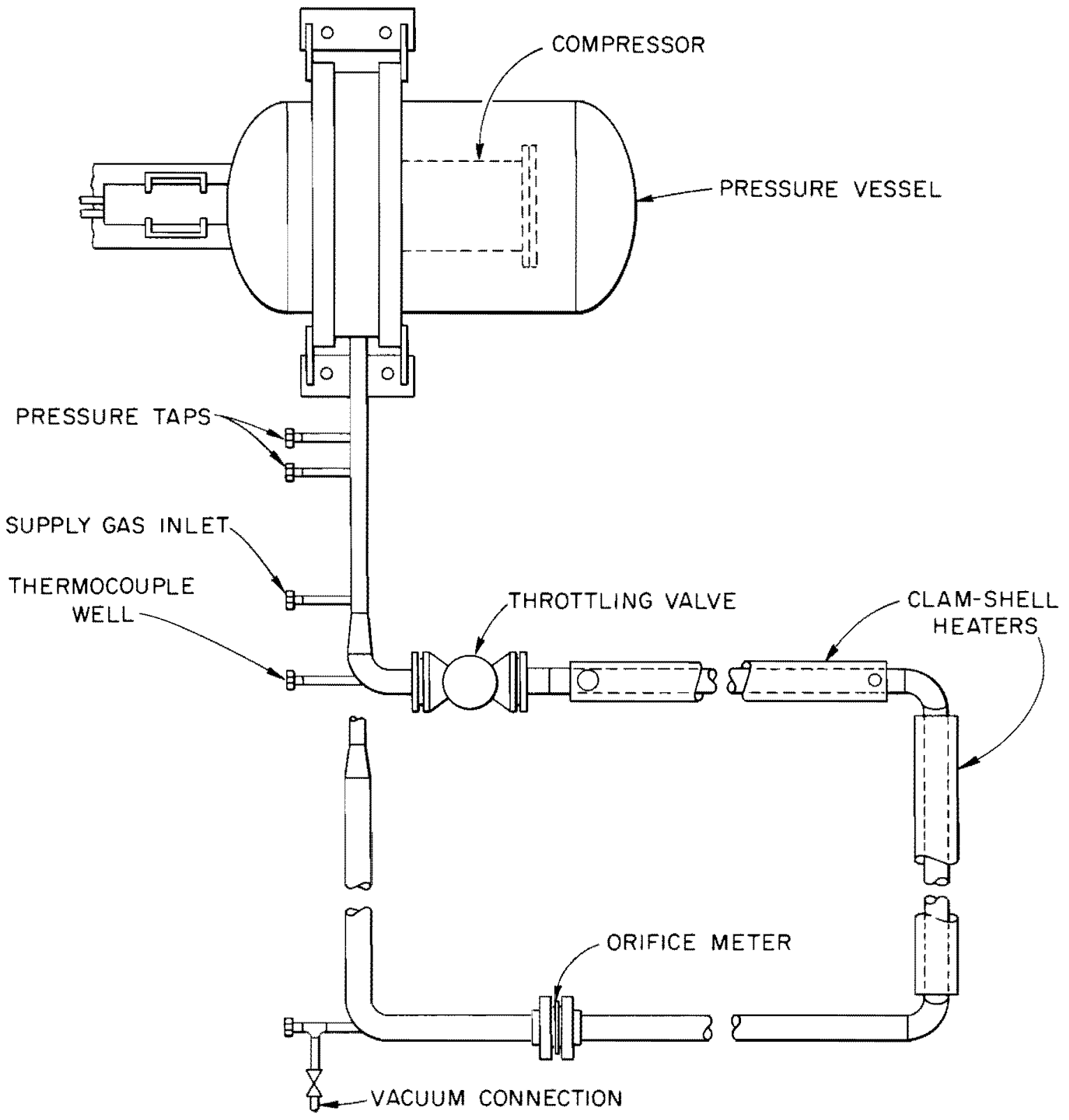

Fig. 6. Diagram of Helium Compressor Test Loop. 
casings. Figure 7 depicts the installation of the capacitance gages in the inboard and outboard casings. Each gage assembly consisted of a thin disc of Kovar (a low-expansion alloy) embedded in heat-resistant glass.

A Fielden proximity meter detected changes in the distance between the gage element and the impeller by measuring the change in capacitance between the two parts. Periodic calibration of the instrument was made so that a reasonably linear relationship could be obtained between mechanical displacement and capacitance.

\section{TEST PROCEDURE}

Prior to installation in the test loop just described, a number of tests were made in a simple cold shakedown stand. The rotary element was operated at room temperature to verify operability of the rotating assembly, including the ball bearings; clearances between the bearing grease seals and the rotating members; and the reliability of the thermocouples. Some difficulties were encountered in the initial operation of the capacitance gages and it was necessary to develop procedures which would permit obtaining reproducible relationships between the observed capacities and the measured mechanical clearances.

During the cold shakedown runs it was found that the clearance between the impeller and the casings seemed to decrease after the unit had been operated for a period of time. The relative decrease was greater on the side of the impeller toward the motor than on the outboard side.

For the first run in the hot test stand, the inboard (motor end) clearance was set at $0.010 \mathrm{in}$. and the outboard clearance was set at $0.007 \mathrm{in}$. (the initial cold test clearances had been 0.007 in. on both sides). Shortly after startup of the hot test, while the loop temperature was being increased, the impeller rubbed against the outboard casing. Subsequent investigations showed that the center portions of the inboard and outboard casings were bending toward the impeller as the temperature was increased, because the expansion of these parts with increasing temperature was restrained by the motor housing (for the inboard casing), and by a pilot diameter in the pressure vessel (for the outboard casing). 


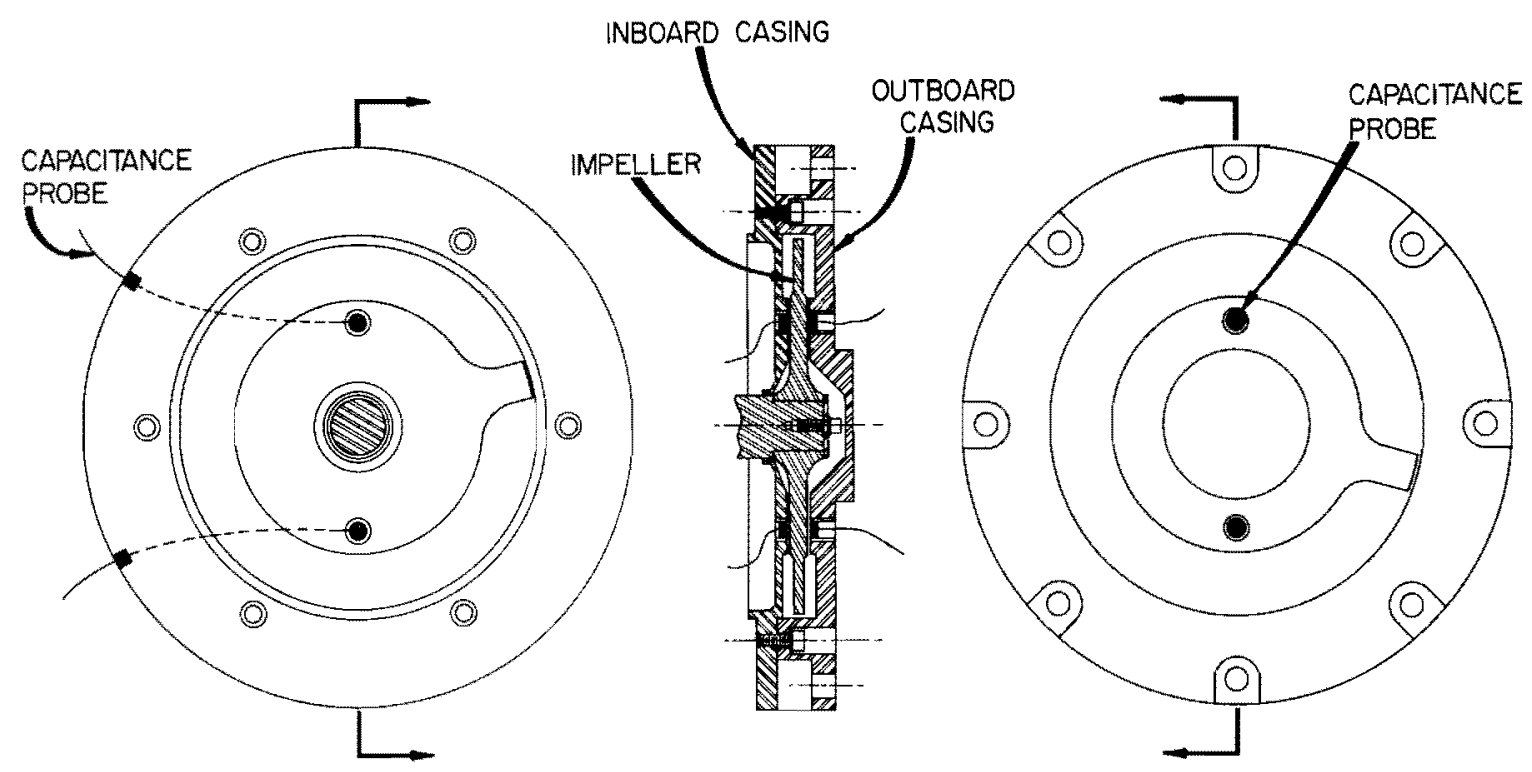

Fig. 7. Regenerative Inpeller Casings with Capacitance Probes. 
This situation was corrected for the outboard casing by providing spacers which moved this part axially away from the pilot diameter so that its growth was not restrained. Since this type of correction could not be applied to the inboard casing, the axial clearance between the impeller and this casing was increased.

The room temperature values of the compressor running clearances were established at 0.015 and 0.025 in., outboard and inboard, respectively, with a 0.009 -in. radial clearance at the splitter (interruption between inlet and discharge flow area). These values permitted operation of the compressor at all conditions from normal room temperature and pressure up to $385 \mathrm{psig}$ and $600^{\circ} \mathrm{F}$. The capacitance gage was found to be a very useful instrument for this work.

\section{TEST RESULTS}

Compressor performance data were obtained at several speeds and at varying helium suction conditions. Figure 8 shows the head-flow characteristics, with values of impeller efficiency and motor power input superimposed, at design conditions of $385 \mathrm{psig}$ and $600^{\circ} \mathrm{F}$. The design objectives (see design point on Fig. 8) were achieved at a moderate compressor speed. The impeller efficiency was calculated by subtracting previously measured no-load motor losses from the measured motor power input values. Since the no-load motor losses were not corrected for the increased $I^{2} R$ losses above no load, there are some minor inaccuracies in these data.

Compressor performance was materially affected by changes in impeller clearances, whether deliberately established or resulting from themal effects. Figure 9 shows the compressor characteristics at design conditions of $385 \mathrm{psig}$ and $600^{\circ} \mathrm{F}$ for two different over-all room-temperature impeller clearance values $(0.040 \mathrm{in}$. and $0.050 \mathrm{in.})$. On the basis of the capacitance gage readings, the 0.040-in. room-temperature impeller clearance valve was reduced to about $0.016 \mathrm{in}$. at design conditions with the spacing equally divided between the front and rear of the impeller. The 0.055 -in. room-temperature impeller clearance value was beyond the range of the capacitance gage, but it was estimated that the hot running clearance was reduced to about $0.030 \mathrm{in}$. In both cases, it was thought that the 


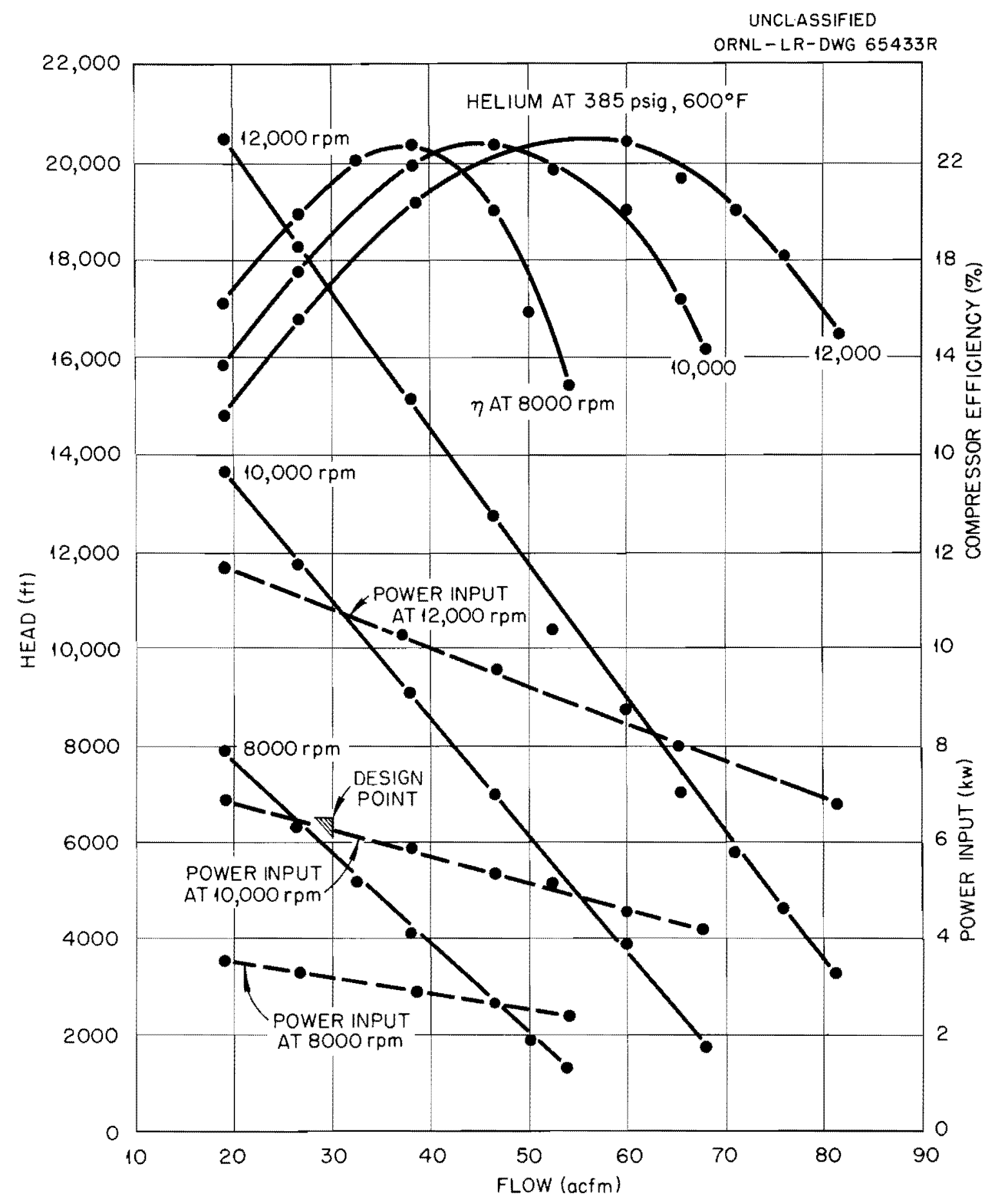

Fig. 8. Performance of Regenerative Compressor (HECT-2 Type). 


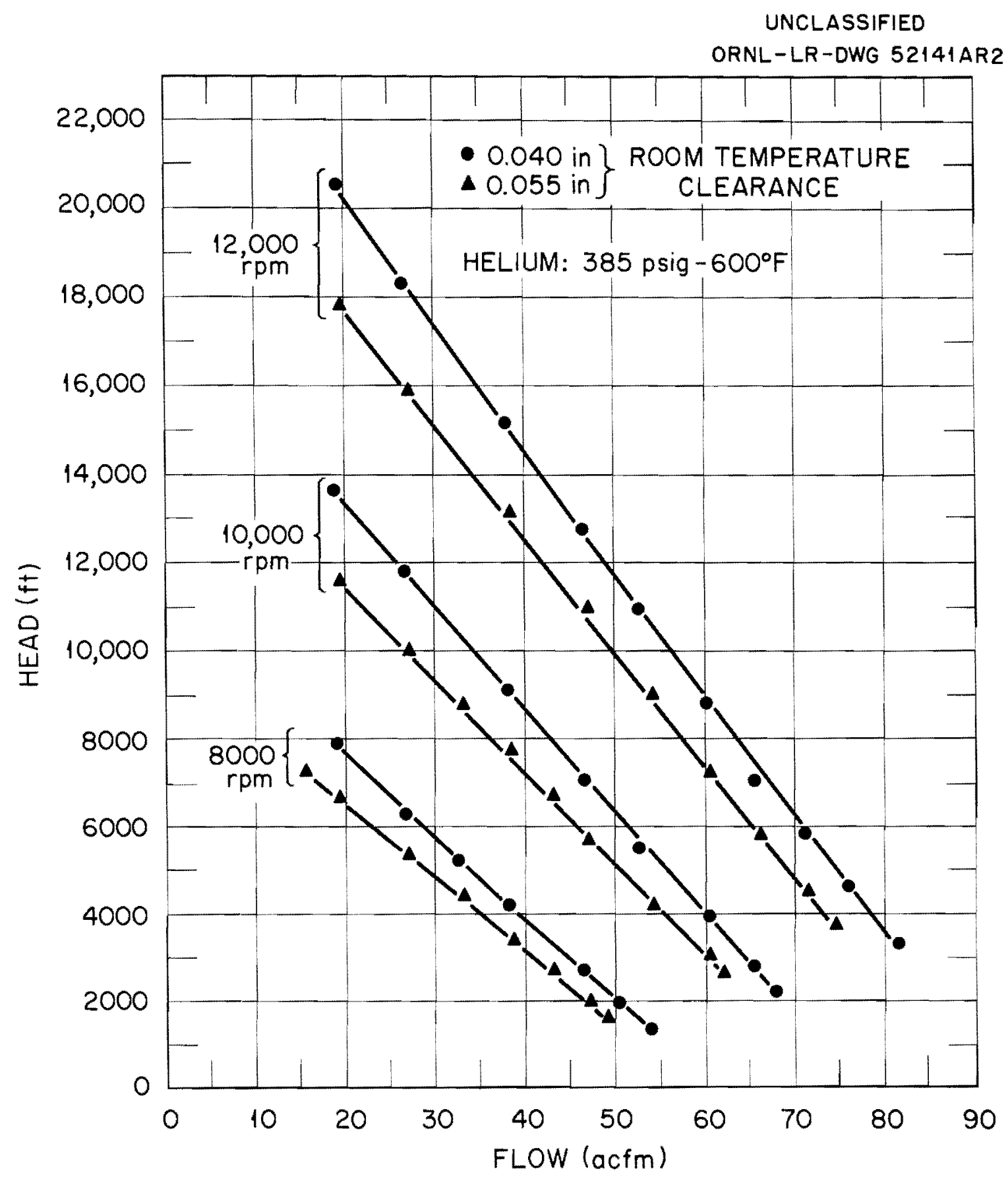

Fig. 9. Head vs Flow, Regenerative Compressor (HECT-2 Type). 
rear impeller clearance was reduced significantly by the thernal distortion of the inboard casing, and that the reduction in the outboard clearance was primarily due to the differential growth of the shaft with respect to the main housing.

Figure 10 shows the compressor performance at two different operating conditions ( $385 \mathrm{psig}$ and $600^{\circ} \mathrm{F}, 165 \mathrm{psig}$ and $100^{\circ} \mathrm{F}$ ). The gas densities were within $15 \%$ of each other. It is suspected that the loss in performance at the lower temperature and pressure is attributable to larger running clearances and hence a greater leakage across the impeller.

The similarity laws for dynamic compressors state that the ratio of volume flows of any given point on a characteristic curve will be directly proportional to the ratio of the speeds, and that the ratio of the values of head will be proportional to the square of the ratio of the speeds. It was found that these laws hold for the test results shown in this report with sufficient accuracy for most practical purposes.

\section{DISCUSSION}

A number of regenerative compressors, similar in design to the prototype unit described in this report, have been built during the past two years. A set of two compressors, connected in series, have been used to circulate the gas coolant (primarily helium) in the No. I forced convection in-reactor test facility at the ORR. Four compressors are assigned to this facility, with two installed, and the other two used as spares. This faclity has been operated for more than 23000 hours.

Three additional regenerative compressors have been built for the No. 2 forced convection in-reactor test facility at the ORR. Two of these units are operated in parallel, with the third unit serving as a spare. The prototype compressor has been used to circulate helium in an out-ofpile facility for tests of various components, including heaters, cooling systems, thermocouples, and a shield plug. A total of more than $26000 \mathrm{hr}$ of operation has been accumulated by the various compressor units.

Since it was not initially known for how long a period the grease lubricated ball bearings could operate without relubrication, a decision was made to replace the bearings after approximately $3500 \mathrm{hr}$ of operation. 


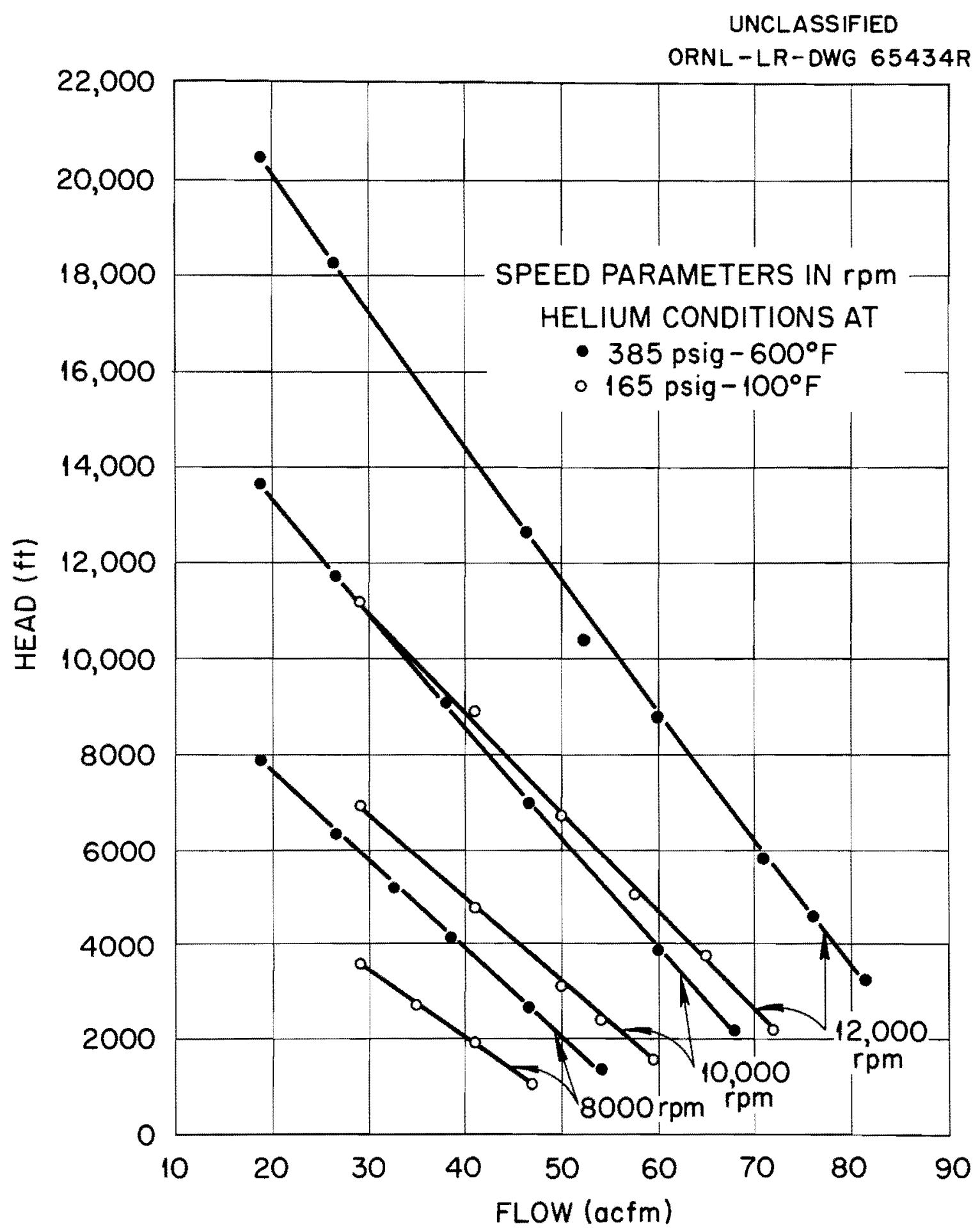

Fig. 10. Head vs Flow, Regenerative Compressor (HECT-2 Type). 
An inspection of the grease in the bearings removed from compressors after some of the earlier test runs indicated that a substantially longer period of operation should be attainable without excessive deterioration. The interval between bearing replacement was then increased to $4500 \mathrm{hr}$ and one compressor has been operated for this interval without evidence of difficulty.

Data on the rate at which grease is lost from the bearings are given in a paper ${ }^{\top}$ presented at a recent meeting.

The problem previously encountered with improper flow distribution in the water cooling passages of the ORNL centrifugal compressor ${ }^{8}$ was found in these regenerative units. The difficulty was remedied by plating the interior of the water passages by the Kanigen (electroless nickel) process. The plating solution was circulated through the water passages for a period of several hours at an appropriate flow and temperature. Although the extent of plating deposition inside the water passages was not fully determined, subsequent tests indicated that the motor and bearing housings were adequately cooled after the plating operation.

If the need should arise to build a substantial number of regenerative compressors of the type discussed in this report, consideration should be given to redesigning the cooling passages so that they would be less expensive to fabricate. The present water cooling passage design was taken directly from that of the centrifugal compressor to avoid the time and costs involved in a redesign. In the centrifugal compressor application helium flowed at a relatively high velocity over a thin shell adjacent to the major diameter of the motor housing, and it was necessary to provide a substantial amount of water cooling for this area. This requirement is not present for the regenerative compressor, since the gas surrounding the motor housing is essentially stagnant. It should, therefore, be possible to provide a simpler cooling geometry for the general arrangement adopted for the regenerative compressor.

${ }^{7}$ I. K. Namba, "The Performance of Grease-Lubricated Ball Bearings in Small Compressors," Rotating Machinery for Gas-Cooled Reactor Application, TID-7631, June 1962, pp 215-227.

${ }^{8} \mathrm{I} \cdot \mathrm{K} \cdot \mathrm{Namba}, \mathrm{pp} \cdot \mathrm{cit} \cdot \mathrm{p} 9$. 


\section{CONCLUSIONS}

As compared to a conventional centrifugal compressor, the regenerative type of compressor described in this report has exhibited the following characteristies:

1. It produces relatively high heads at very low flow rates.

2. No surging problems have been encountered at any value of flow down to and including shutoff.

3. The slope of the head-capacity curve is very nearly linear for this particular aerodynamic configuration.

4. At any constant speed the motor power requirements decrease as the flow is increased.

5. The aerodynamic efficiency of this type of compressor is relatively low.

The primary use of the regenerative compressor appears to lie in those areas where high head requirements (high values of pressure rise) are combined with low volumetric or mass flow requirements. In such cases one regenerative compressor can be used to replace two or three centrifugal compressors connected in series, and can be operated at lower volumetric flows than the latter type of compressor without surging. While positive displacement compressors could produce combinations of head and flow similar to those of the regenerative compressor, all positive displacement units studied to date give rise to problems of excessive gas outleakage, mechanical difficulties, and large size.

\section{ACKNOWLEDGMENTS}

A number of individuals made important contributions to the development of the regenerative compressor. The aerodynamic design was computed by G. Samuels and R. S. Holcomb. The mechanical design was carried out by W. G. Cobb and L. V. Wilson. The development work was guided by W. F. Boudreau and A. G. Grindell. S. M. DeCamp, J.W. Krewson, D. L. Gray, and $W$. K. Stair contributed materially to the development activities. 


\section{Internal Distribution}

I. S. E. Beall

2. M. Bender

3. A. L. Boch

4. W. F. Boudreau

5. R. B. Briggs

6. D. W. Cardwell

7. W. G. Cobb

8. J. A. Conlin

9. S. M. DeCamp

10. A. P. Fraas

11. J. K. Franzreb

12. C. H. Gabbard

13. P. A. Gnadt

14. D. L. Gray

15. A. G. Grindell

16. R. S. Holcomb

17. R. B. Korsmeyer

18. T. S. Kress

19. J. W. Krewson

20. M. I. Lundin

21. R. N. Lyon

22. H. G. MacPherson

23-43. W. D. Manly
44. A. J. Miller

45-52. I. K. Namba

53. A. M. Perry

54. M. W. Rosenthal

55. G. Samuels

56. H. W. Savage

57. A. W. Savolainen

58. M. J. Skinner

59. P. G. Smith

60. I. Spiewak

6I. W. K. Stair

62. E. Storoo

63. J. A. Swartout

64. E. R. Taylor

65. D. B. Trauger

66. L. V. Wilson

67. H. C. Young

68. J. Zasler

69-71. Central Research Library (CRL)

72-74. Y-12 Document Reference Section (DRS)

75-76. Laboratory Records Department (IRD)

77. Laboratory Records Department, Record Copy (IRD-RC)

External Distribution

78-92. Division of Technical Information Extension (DTIE)

93. Research and Development Division, ORO

94-95. Reactor Division, ORO 
